\title{
PRAVNO REGULISANJE PLATFORMI ZA RAZMENU VIDEO SADRŽAJA U REVIDIRANOJ DIREKTIVI O AUDIOVIZUELNIM MEDIJSKIM USLUGAMA
}

\begin{abstract}
Saša SIMOVIĆ*
Apstrakt: Usvajanjem izmena i dopuna Direktive o audiovizuelnim medijskim uslugama, Evropska unija je proširila pojam audiovizuelnih medijskih usluga na platforme za razmenu video sadržaja. Novi pristup znači i nove obaveze za države članice, ali i odgovor Evropske unije na sve veći uticaj interneta kao medija. Ovaj članak daje pregled novina u Direktivi, sa posebnim osvrtom na ključni deo - a to su platforme za razmenu video sadržaja. U radu su predstavljeni i potencijalni izazovi i rešenja u sprovođenju novih mera, kako za države članice Evropske unije tako i za Republiku Srbiju.

Ključne reči: Direktiva o audiovizuelnim medijskim uslugama, platforme za razmenu video sadržaja, Evropska unija, mediji.
\end{abstract}

\section{1) UVOD}

U novembru 2018. godine usvojena je Direktiva (EU) 2018/1808 Evropskog parlamenta i Saveta o izmenama i dopunama Direktive 2010/13/EU o koordinaciji određenih zakonskih odredbi, regulaciji ili upravnim radnjama u državama članicama koje se tiču pružanja audiovizuelnih medijskih usluga (Direktiva o audiovizuelnim medijskim uslugama), sa aspekta promenjenih okolnosti na medijskom tržištu. ${ }^{1}$

\footnotetext{
* Saša Simović, Viši pravni savetnik, Regulatorno telo za elektronske medije.

E-mail: sasa.simovic@rem.rs.

1 "Directive (EU) 2018/1808 of the European Parliament and of the Council of 14 November 2018 amending Directive 2010/13/EU on the coordination of certain provisions laid down by law, regulation or administrative action in Member States concerning the provision of audiovisual media services (Audio-visual Media Services Directive) in view of changing market realities", Official Journal of the European Union L 303/69, 28 November 2018.
} 
Direktive, kao pravni akti sekundarnog prava EU Acquis-a, koje donose institucije Evropske unije, ne primenjuju se direktno u državama članicama kao što se to čini sa uredbama, već je neophodno da se direktive transponuju u nacionalna zakonodavstva. ${ }^{2}$ Rok za transponovanje navedene Direktive o audiovizuelnim medijskim uslugama, odnosno inkorporiranje u nacionalna zakonodavstva država članica Evropske unije je 21 mesec, odnosno septembar 2020. godine. ${ }^{3}$

Revidirana Direktiva o audiovizuelnim medijskim uslugama ima za cilj da podstiče jačanje zaštite maloletnika od škodljivih sadržaja i neprikladnog oglašavanja, da ojača nezavisnost nacionalnih regulatora audiovizuelnih medijskih usluga, kao i da promoviše evropska audiovizuelna dela, određujući udeo od 30\% u katalozima pružalaca audiovizuelnih medijskih usluga na zahtev, odnosno on demand.

Takođe, odredbe revidirane Direktive o audiovizuelnim medijskim uslugama dodatno učvršćuju princip države porekla kao osnove regulacije audiovizuelnih medija u državama članicama Evropske unije i redefiniše ograničenja u vezi sa oglašavanjem. Revidirana Direktiva o audiovizuelnim medijskim uslugama održala je princip države porekla, što znači da pružaoci medijskih usluga moraju samo da se pridržavaju pravila jedne države članice u kojoj su osnovani. Pored toga, prema novim pravilima za oglašavanje u vezi sa emitovanjem, odnosno pružanjem linearnih usluga, umesto da se ograničenje reklama koje se primenjuje po satu ( $\mathrm{t}$. ograničavanje oglašavanja na najviše 12 minuta po satu, što iznosi $20 \%$ vremena emitovanja u svakom satu bez obzira na doba dana), dvadesetpostotna granica oglašavanja sada će se primenjivati na dva duža vremenska termina - period od 12 sati, između 6:00 časova i 18:00 časova, kao i period od 6 sati između 18:00 časova i ponoći. Ovo pružaocima medijskih usluga nudi veću fleksibilnost da prilagode periode oglašavanja tokom dana, omogućavajući im da dodele do 144 minuta oglašavanja u periodu između 6:00 časova i 18:00 časova, a ukupno 72 minuta između 18:00 časova i ponoći, bez posebnih ograničenja za količinu oglašavanja koja se nude tokom emitovanja između ponoći i 6:00 časova. ${ }^{4}$

Osim toga, obim primene određenih pravila definisanih Direktivom o audiovizuelnim medijskim uslugama proširuje se na platforme za razmenu video

\footnotetext{
2 „Upoznavanje Evropske unije: Kako funkcioniše EU”, Služba za publikacije Evropske unije, 2014, str. 5, dostupno na: http://publications.europa.eu/resource/cellar/ab3422af-969a-11e7-b92d01aa75ed71a1.0002.03/DOC_1, datum pristupa: 01.10.2020. godine.

${ }^{3}$ Zvaničan sajt Evropske komisije, Revizija Direktive o audiovizuelnim medijskim uslugama, dostupno na: https://ec.europa.eu/digital-single-market/en/revision-audiovisual-mediaservices-directive-avmsd, datum pristupa: 10.10.2020. godine.

${ }^{4}$ Karol Laskowski, "Poland: Changes To The Audiovisual Media Services Directive - What Does It Mean For The Media Market?", Mondaq, 5 April, 2019, dostupno na: https://www. mondaq.com/broadcasting-film-tv-radio/795192/changes-to-the-audiovisual-media-servicesdirective-what-does-it-mean-for-the-media-market, datum pristupa: 12.10.2020. godine.
} 
sadržaja (eng. Video sharing platforms), koje sada imaju obavezu da obezbede odgovarajuće mere zaštite.

\section{2) ŠTA SU TO PLATFORME ZA RAZMENU VIDEO SADRŽAJA?}

Jedna od najznačajnijih novina, koja se uvodi izmenama Direktive Evropske unije o audiovizuelnim medijskim uslugama iz 2018. godine, jeste regulisanje platformi za razmenu video sadržaja. Do usvajanja izmena Direktive o audiovizuelnim medijskim uslugama, platforme za razmenu video sadržaja nisu spadale u audiovizuelne medijske usluge, već u usluge informacionog društva. ${ }^{5}$ Izmenama navedene Direktive proširiće se pojam audiovizuelnih medijskih usluga i na platforme za razmenu video sadržaja, pored već postojećih linearnih i nelinearnih usluga. ${ }^{6}$

U revidiranoj Direktivi, platforma za razmenu video sadržaja je definisana kao komercijalna usluga adresirana za javnost, prema kojoj je glavna svrha usluge (ili suštinska funkcionalnost takve usluge) pružanje programa i video zapisa, koje generiše korisnik široj javnosti u cilju informisanja, zabavljanja ili edukovanja, a za koje platforme za razmenu video sadržaja nemaju uredničku odgovornost koja je dostupna putem elektronskih komunikacijskih mreža i gde je sadržaj organizovan na način koji odredi platforma za razmenu video sadržaja, posebno za prikazivanje, tagovanje i sekvenciranje. ${ }^{7}$

To dalje znači da će usluge poput Youtube-a biti obuhvaćene revidiranom Direktivom o audiovizuelnim medijskim uslugama i da će audiovizualni sadržaj podeljen na društvenim mrežama, kao što je Twitter, takođe biti obuhvaćen revidiranom Direktivom. ${ }^{8}$

\footnotetext{
5 “Directive 2000/31/EC of the European Parliament and of the Council of 8 June 2000 on certain legal aspects of information society services, in particular electronic commerce, in the Internal Market ('Directive on electronic commerce')", Official Journal L 178, 17 July, 2000.

${ }^{6}$ Maja Zarić, „Audiovizuelna politika Evropske unije sa posebnim osvrtom na Direktivu o audiovizuelnim medijskim uslugama", Evropsko zakonodavstvo 55/16, Institut za međunarodnu politiku i privredu, 2016, str. 360.

7 "Directive (EU) 2018/1808 of the European Parliament and of the Council of 14 November 2018 amending Directive 2010/13/EU on the coordination of certain provisions laid down by law, regulation or administrative action in Member States concerning the provision of audiovisual media services (Audiovisual Media Services Directive) in view of changing market realities", op. cit., article 1.

${ }^{8}$ Lubos Kuklis, "Media regulation at a distance: video-sharing platforms in AVMS Directive and the future of content regulation", Medialaws, 2020, p. 98, dostupno na: http://www.media laws.eu/wp-content/uploads/2020/07/RDM_2_2020-Kuklis.pdf, datum pristupa: 20.10.2020. godine.
} 
Iako veb-stranice novina ostaju izvan okvira Direktive, samostalni delovi tih stranica sa audiovizuelnim programom ili video zapisima, koje generiše korisnik, smatraće se platformom za razmenu video sadržaja za potrebe revidirane Direktive. Međutim, svaka povremena upotreba video zapisa na veb-lokacijama, blogovima, kao i informativnim portalima, ostaće izvan okvira Direktive o audiovizuelnim medijskim uslugama.

S obzirom na to da se definicija platforme za razmenu video sadržaja može oceniti kao, donekle, široka, a takođe, imajući u vidu, da nove tehnologije iz dana u dan napreduju, Evropska komisija je donela smernice kojima bi, između ostalog, pomogla državama i nacionalnim regulatornim telima da definišu preciznije šta je to sve platforma za razmenu video sadržaja i na osnovu čega će se utvrđivati da li određena usluga spada u platformu za razmenu video sadržaja ili ne. ${ }^{9}$

Dalje, revidirana Direktiva propisuje i kriterijume za zasnivanje nadležnosti države nad pružaocima platforme za razmenu video sadržaja. To znači da postoje jasni kriterijumi i uslovi koji određuju kada je jedna država nadležna ili nije nadležna za određenu platformu za razmenu video sadržaja. Osim toga, uspostavlja se obaveza prema državama članicama Evropske unije da obaveštavaju Evropsku komisiju o tome koji su pružaoci pod njihovom jurisdikcijom, kao i obaveza vođenja i održavanja baze podataka o pružaocima pod njihovom nadležnošću radi osiguranja transparentnosti.

\section{3) KOJE SU TO NOVE OBAVEZE PREMA REVIDIRANOJ DIREKTIVI I KO SE ŠTITI ISTOM?}

Nove obaveze za države jesu da se osigura da platforme za razmenu video sadržaja uspostave mere u cilju zaštite:

(1) maloletnika od štetnih sadržaja (koji mogu narušiti njihov fizički ili mentalni razvoj);

(2) javnosti od podsticanja na nasilje ili mržnju; i

(3) javnosti od sadržaja kojim se izvršava krivično delo (javna provokacija radi činjenja terorističkih dela, dečja pornografija i rasizam ili ksenofobija). ${ }^{10}$

\footnotetext{
9 "Communication from the Commission Guidelines on the practical application of the essential functionality criterion of the definition of a 'video-sharing platform service' under the Audiovisual Media Services Directive 2020/C 223/02", Official Journal of the European Union C 223/3, 7 July, 2020, dostupno na: https://eur-lex.europa.eu/legal-content/EN/TXT/?uri= uriserv:OJ.C_.2020.223.01.0003.01.ENG\&toc=0J:C:2020:223:TOC, datum pristupa: 18.10 . 2020. godine.

10 "Directive (EU) 2018/1808 of the European Parliament and of the Council of 14 November 2018 amending Directive 2010/13/EU on the coordination of certain provisions laid down
} 
Mere navedene u Direktivi o audiovizuelnim medijskim uslugama koje će platforme za razmenu video sadržaja morati da ispune, uključuju mehanizme za označavanje i izveštavanje, sisteme verifikacije starosne dobi, sisteme za ocenjivanje sadržaja od strane prenosioca, ili korisnika, ili roditeljskog sistema kontrole, kao i pojašnjenje u uslovima platforme o zabrani korisnicima da dele sadržaj od kojeg građani treba da budu zaštićeni. Naravno, nacionalne vlasti (uglavnom regulatorna tela) imaće obavezu provere da li su platforme usvojile odgovarajuće mere.

U ovom delu dobija se odgovor na pitanje ko se i na koji način štiti odredbama revidirane Direktive. Odredbama revidirane Direktive štite se maloletnici od štetnih sadržaja, štiti se javnost od podsticanja na nasilje ili mržnju, kao i od sadržaja kojima se izvršava krivično delo (kao što je terorizam, rasizam, pornografija ili ksenofobija).

Ono što se može zaključiti jeste da se obaveze i mere koje moraju preduzeti platforme za razmenu video sadržaja ne mogu regulisati na način na koji su regulisane obaveze „tradicionalnih” medija. Kod platformi za razmenu video sadržaja, za razliku od „tradicionalnih" medija (kao što je audiovizuelna medijska usluga i medijska usluga radija), ne postoji uređivačka odgovornost, pa samim tim se ne mogu široko postaviti odgovornost i obaveze platforme za razmenu video sadržaja za regulisanje sadržaja koje generišu korisnici. Uređivačka odgovornost je odgovornost za sprovođenje kontrole nad izborom programskih sadržaja i njihovom organizacijom, bilo da je reč o redosledu pružanja prema hronološkoj šemi ili o pružanju sadržaja na zahtev na osnovu kataloga. Imajući u vidu da kod platforme za razmenu video sadržaja ne postoji uređivačka odgovornost, jer ne postoji kontrola nad izborom programa, sledi da obaveze i mere koje moraju biti preduzete, kao i zaštitni objekti, jesu definisani na drugačiji način nego kod „tradicionalnih" pružalaca medijske usluge. Operatori platforme za razmenu video sadržaja ne mogu direktno, po metodu uređivačke odgovornosti, da sprovode kontrolu nad izborom programskih sadržaja i njihovom organizacijom, ali to ne znači da neće morati da preduzmu određene mere kojima će zaštititi gore navedena dobra od štetnih sadržaja.

Takođe, još jedna intencija zakonodavca jeste da se ohrabri primena novog režima putem koregulacije. ${ }^{11}$ Suština regulisanja platforme za razmenu video sadržaja nije da država, odnosno nacionalna regulatorna tela "kontrolišu” internet, što je praktično i teško ostvarivo, već da sami operatori platforme za razmenu video sadržaja preduzmu određene mere gde će tim putem učiniti internet bezbednijim mestom. To sve znači da država, tj. regulatorna tela, neće biti više prva u redu da „regulišu”, već će to raditi i pružaoci platformi za razmenu video sadržaja. Pored

\footnotetext{
by law, regulation or administrative action in Member States concerning the provision of audiovisual media services (Audiovisual Media Services Directive) in view of changing market realities", op. cit., article 28. b.

${ }^{11}$ Ibid.
} 
toga, prema revidiranoj Direktivi o audiovizuelnim medijskim uslugama, pružaoci platforme za razmenu video sadržaja takođe bi morali poštovati određene obaveze za komercijalne komunikacije za koje su odgovorni.

\section{4) SPROVOĐENJE I SANKCIJE}

Kada je reč o sprovođenju revidirane Direktive o audiovizuelnim medijskim uslugama, države članice Evropske unije imale su rok do septembra 2020. godine da transponuju direktivu u svoje zakonodavstvo. Osnovni zadatak država članica je da osiguraju da pružaoci platforme za razmenu video sadržaja u njihovoj nadležnosti ispunjavaju obaveze i izvršavaju gore navedene mere. Potom, države će morati da vode ažurnu evidenciju o svim pružaocima platforme za razmenu video sadržaja pod njihovom nadležnošću, kao i da listu svih pružalaca platforme za razmenu video sadržaja dostave Evropskoj komisiji. ${ }^{12}$

U pogledu sankcionisanja, države će biti dužne da se obezbedi mehanizam za podnošenje prigovora i nepristrasno rešavanje sporova. Način na koji će se regulisati ovo pitanje još uvek nije jasan i zavisiće od države do države, što znači da neće postojati jedinstveni metod. Takođe, države će biti u obavezi da osiguraju korisnicima da mogu ostvariti svoja prava i pred sudom, a sve u vezi sa platformom za razmenu video sadržaja. ${ }^{13}$

\section{5) POTENCIJALNI IZAZOVI U SPROVOĐENJU}

Što se tiče definisanja platforme za razmenu video sadržaja, kao i na koji način će se definisati njena suštinska funkcionalnost, Evropska komisija je donela smernice ${ }^{14}$ (koje nisu obavezujuće) kojima će, između ostalog, pomoći državama članicama i nacionalnim regulatornim telima da, s jedne strane, definišu preciznije šta je to sve platforma za razmenu video sadržaja i da, s druge stane, odrede na osnovu čega će se utvrđivati da li određena usluga spada u platformu za razmenu video sadržaja ili ne. Ideja jeste bila da se izbegne rigidnost pri definisanju, uz zaključak da je suštinsku funkcionalnost platforme najpodobnije definisati na osnovu niza indikatora. Samu procenu samostalno će vršiti nacionalni regulatori. Evropska komisija je predstavila sledeće grupe indikatora koji se moraju uzeti u obzir:

\footnotetext{
${ }^{12}$ Ibid.

${ }^{13}$ Ibid.

14 "Communication from the Commission Guidelines on the practical application of the essential functionality criterion of the definition of a 'video-sharing platform service' under the Audiovisual Media Services Directive 2020/C 223/02", op. cit.
} 
- Prva grupa indikatora jeste u vezi sa odnosom između audiovizuelnog sadržaja i glavne ekonomske aktivnosti (celokupna arhitektura i izgled platforme, samostalna priroda audiovizuelnog sadržaja, posebne funkcionalnosti usluge i način na koji se pozicionira na tržištu);

- Druga grupa indikatora donosi pitanja u vezi sa kvantitetom i kvalitetom usluge: količina audiovizuelnog sadržaja na određenoj platformi, stepen izloženosti korisnika audiovizuelnom sadržaju i stepen popularnosti određene platforme, da li se dele sadržaji koji su samostalnog karaktera, tj. nisu u uskoj vezi sa samom platformom, da li sadržaj ima posebne karakteristike koje će privući pažnju publike i slično;

- Treća grupa indikatora je u vezi sa monetizacijom audiovizuelnog sadržaja ili ostvarivanja prihoda od njega (ugovori o sponzorstvu na platformi, uslovni pristup i sl.);

- Četvrta grupa bazira se na dostupnosti alata koji poboljšavaju uočljivost i atraktivnost određenog audiovizuelnog medijskog sadržaja.

Pored toga, jedan od važnijih izazova u vezi sa prenošenjem i daljom primenom revidirane Direktive, kada je reč o platformama za razmenu video sadržaja, biće pravljenje razlike između odluka koje platforme za razmenu video sadržaja donose $\mathrm{u}$ isključivoj primeni sopstvenih uslova korišćenja (eng. Terms of Service - ToS) i odluka donetih u njihovoj novoj ulozi kao izvršilaca nacionalnih zakona. ${ }^{15}$ To može pokrenuti poremećaje u tumačenju odredbi i može negativno uticati na prava korisnika, posebno na slobodu izražavanja. Treba imati u vidu da se uslovi korišćenja (ToS) mogu menjati samo od strane operatora platforme za razmenu video sadržaja, i da to de facto nije ugovorni odnos između korisnika i operatora platforme za razmenu video sadržaja, iako se prikazuje kao takav.

Problem nastaje kada se platforme za razmenu video sadržaja suoče sa situacijom da primena restrikcije u vezi sa određenim sadržajem može biti ocenjena od strane korisnika, ali i sa zakonskog stanovišta, kao „preterana”, a da operator platforme za razmenu video sadržaja tvrdi da su primenjivana samo njihova interna pravila, odnosno uslovi korišćenja (ToS). Na primer, uzmimo da operator platforme za razmenu video sadržaja odluči da ukloni određeni sadržaj, jer isti predstavlja čin označen kao govor mržnje, dok korisnik koji je postavio osporeni sadržaj tvrdi da je to primeren govor, jer ne predstavlja govor mržnje prema važećim zakonima. Operator platforme za razmenu video sadržaja može lako tvrditi da je sadržaj skinut ne na osnovu ograničenja govora mržnje sadržanih u zakonu, već na osnovu sopstvene šire definicije pojma govora mržnje u uslovima korišćenja. U tom

${ }^{15}$ Joan Barata, "New EU rules on video-sharing platforms: will they really work?", CIS Stanford Law School, 2019. dostupno na: https://cyberlaw.stanford.edu/blog/2019/02/new-eu-rulesvideo-sharing-platforms-will-they-really-work\#.XGptiYyaUVA.twitter, datum pristupa: 21.10.2020. godine. 
kontekstu, odluka platforme bila bi u potpunosti legitimna i u principu se ne mogu primeniti mogući mehanizmi spoljne revizije.

Takođe, postavlja se pitanje na koji način će regulatorna tela davati ovlašćenje pružaocima platforme za razmenu video sadržaja za pružanje usluge, odnosno da li će to biti izdavanje dozvole, odobrenja ili samo notifikacija i upis u odgovarajući registar. Ono što se može pretpostaviti jeste da će se većina država odlučiti da ne izdaju dozvole, već da će ovlašćenje svoditi na davanje odobrenja ili obaveštenje, zbog jednostavnosti procedure.

\section{6) REPUBLIKA SRBIJA I REVIDIRANA DIREKTIVA}

Republika Srbija na putu pristupanja Evropskoj uniji ima obavezu da uskladi svoje zakonodavstvo sa pravom Evropske unije. ${ }^{16}$ To dalje znači da će Srbija, iako država kandidat, biti u obavezi da transponuje revidiranu Direktivu o audiovizuelnim medijskim uslugama u domaće zakonodavstvo i da taj proces, koji će podrazumevati ili donošenje novih propisa ili izmenu i dopunu postojećih, mora biti inkluzivan, koordinisan i transparentan.

Što se tiče usklađivanja srpskog zakonodavstva sa pomenutom revidiranom Direktivom o audiovizuelnim medijskim uslugama, odnosno pre nego što se uopšte krene u razmatranje izmene zakona ili donošenja novih zakona u toj oblasti, bilo bi potrebno izvršiti detaljnu analizu trenutnog stanja. Ta analiza trebalo bi da utvrdi u kojoj meri su trenutno važeći zakoni usklađeni sa izmenjenom Direktivom o audiovizuelnim medijskim uslugama. Ona bi, potom, trebalo da pokaže koje su to oblasti koje treba regulisati novim propisima, kao i koje bi sve zakone trebalo izmeniti, ali i da li je neophodno doneti nove zakone ili je dovoljno izmeniti postojeće. Zatim, relevantna analiza dala bi odgovor na pitanje (kada govorimo o platformama za razmenu video sadržaja) da li uopšte postoje platforme za razmenu video sadržaja u Srbiji za koje bi, po propisanim kriterijumima iz revidirane Direktive o audiovizuelnim medijskim uslugama, Republika Srbija bila nadležna, kao i da, ako postoje, koje su to platforme koje bi potpadale pod budući režim regulacije. Na kraju, ali ne najmanje važno, trebalo bi dobiti i odgovor na pitanje da li će regulisanje navedenih platformi imati uticaj na relevantno medijsko tržište u Srbiji i, ako je odgovor pozitivan, u kojoj meri.

U slučaju da se ustanovi da u Republici Srbiji već postoje platforme za razmenu video sadržaja, trebalo bi sastaviti listu potencijalnih pružalaca i za njih organizovati obuke kroz koje bi se upoznali sa pravilima iz izmenjene Direktive o audiovizuelnim medijskim uslugama. Na tim obukama trebalo bi objasniti zašto je Direktiva

16 „Sporazum o stabilizaciji i pridruživanju između Evropskih zajednica i Republike Srbije”, dostupno na: https://www.mei.gov.rs/upload/documents/sporazumi_sa_eu/ssp_prevod_ sa_anexima.pdf, datum pristupa: 01.09.2020. godine. 
revidirana, kao i koje su to obaveze i novine koje će se ticati njih, a koje će biti predviđene u budućnosti i srpskim zakonodavstvom.

Što se tiče predloga budućih zakonskih rešenja, trebalo bi postaviti sistem koregulacije za većinu novina. To bi bio sistem po kojem bi industrija sama preuzela vodeću ulogu u postavljanju i sprovođenju najvažnijih standarda, dok bi regulator bio ovlašćen da interveniše kao krajnje sredstvo.

Pored toga, potrebno je rešiti na koji način bi srpsko regulatorno telo trebalo da daje ovlašćenje za pružanje usluge platforme za razmenu video sadržaja. Najsvrsishodnije rešenje bilo bi u vidu obaveze da operatori platformi za razmenu video sadržaja podnesu određenu vrstu prijave Regulatornom telu za elektronske medije, bez prethodnog pribavljanja dozvole, ali uz upis u Registar medijskih usluga. To bi omogućilo Regulatornom telu za elektronske medije da identifikuje, nadgleda i procenjuje usaglašenost platformi sa nametnutim obavezama koje su pod njenom nadležnošću, ali i da vodi bazu podataka o postojećim platformama za razmenu video sadržaja.

Kada je reč o merama koje je neophodno da preduzme pružalac platforme za razmenu video sadržaja, a sve u cilju zaštite maloletnika i javnosti od štetnih sadržaja, najbolje bi bilo da zakon, u tom segmentu, postavi samo jasne okvire a da same mere i uslovi za njihovo sprovođenje budu detaljnije razrađeni kroz podzakonske akte. Cilj bi bio ne opterećivati zakonski tekst, a posebno imajući u vidu da se, s jedne strane, radi o novoj oblasti a da je, s druge strane, procedura za izmenu podzakonskog akta nesporno jednostavnija od procedure za izmenu zakona.

U vezi sa zaštitom prava korisnika od strane pružalaca platforme za razmenu video sadržaja, a imajući u vidu da je najavljeno da neće biti jedinstvenog metoda koji će se primenjivati u svim državama članicama EU, trebalo bi sačekati i videti koje će se rešenje pokazati kao najdelotvornije. Takođe, kada govorimo o sudskoj zaštiti korisnika, moramo imati u vidu da će biti neophodno upoznati sudije sa ovom tematikom. Od neizmerne važnosti za sudije biće da budu organizovane kvalitetne obuke iz ove oblasti, kako bi mogli blagovremeno i efikasno delati u novim kompleksnim situacijama.

\section{7) ZAKLJUČAK}

Revidirana Direktiva o audiovizuelnim medijskim uslugama stupila je na snagu u novembru 2018. godine, i države članice EU imale su rok do septembra 2020. godine da transponuju direktivu u svoje nacionalno zakonodavstvo. Fokus prilikom transponovanja, ali i primene revidirane Direktive o audiovizuelnim medijskim uslugama, biće na platformi za razmenu video sadržaja. Najveći izazov biće pronalaženje granice između poštovanja slobode govora i primene pravila koja se tiču platforme za razmenu video sadržaja. Neophodno je da se regulisanjem platforme za razmenu video sadržaja ne postigne kontraefekat, i da se ne desi da 
se primenom pravila, umesto zaštite korisnika, dovedu u pitanje fundamentalna prava korisnika platforme za razmenu video sadržaja, kao što je sloboda govora, mišljenja i izražavanja.

Na kraju, potrebno je da naša država, kao kandidat za pristupanje Evropskoj uniji, odgovori na navedene izazove prilikom transponovanja i primene revidirane Direktive o audiovizuelnim medijskim uslugama. Taj proces podrazumeva ne samo usklađivanje prava, već i preduzimanje aktivnosti koje bi prethodile svemu tome.

Kao što se vidi, postoji dosta izazova, a na nadležnim telima država članica i država kandidata je da se uhvate u koštac sa navedenim problemima.

\section{8) LITERATURA}

Gorwa, R., Garton, A. T., "Democratic Transparency in the Platform Society", Social Media and Democracy: The State of the Field(Cambridge), NatePersily and Josh Tucker, 2020, pp. 1-25.

Kuklis, L., "Media regulation at a distance: video-sharing platforms in AVMS Directive and the future of content regulation", Medialaws, 2020, pp. 95-110.

Zarić, M., „Audiovizuelna politika Evropske unije sa posebnim osvrtom na Direktivu o audiovizuelnim medijskim uslugama", Evropsko zakonodavstvo 55/16, Institut za međunarodnu politiku i privredu, 2016, str. 356-368.

\section{LEGAL REGULATION OF VIDEO SHARING PLATFORMS IN THE REVISED AUDIOVISUAL MEDIA SERVICES DIRECTIVE}

Summary: By adopting amendments to the Audiovisual Media Services Directive, the European Union has extended the concept of audiovisual media services to video-sharing platforms. The new approach also means new obligations for the member states, but also the European Union's response to the growing influence of the Internet as a mass medium. This article provides an overview of the novelties in the Directive, with special reference to a key part, which is video sharing platforms. The paper also presents potential challenges and solutions in the implementation of new measures, both for the member states of the European Union and the Republic of Serbia.

Keywords: Audiovisual Media Services Directive, video sharing platforms, European Union, media. 